\title{
Modelo didático do género exposição escrita: identificação e avaliação dos resultados da sua implementação na qualidade dos textos que os alunos produzem
}

\author{
Didactic model of the genre written exposition: \\ identification and evaluation of the results implementation \\ on the quality of the texts produce by the students
}

Mariana Oliveira Pinto

Professora Adjunta - Departamento de Ciências da Educação e da Linguagem - Escola Superior de Educação Instituto Politécnico de Setúbal, Portugal

\section{RESUMO}

Neste texto são apresentados alguns resultados de um estudo no qual procurámos analisar e perceber de que modo as práticas de escrita que os professores implementam influenciam a qualidade dos textos que os alunos produzem. Para tal, definimos um objetivo geral: avaliar se um dispositivo didático, o Modelo Didático do Género (MDG), implementado de forma explícita e intencional, pode refletir-se, e a que níveis, na qualidade dos textos que os alunos produzem. O estudo foi realizado no contexto de um programa de formação e envolveu 14 professores dos três ciclos do ensino básico. Os resultados apresentados neste artigo procuram evidenciar as características dos textos produzidos pelos alunos do $4^{\circ}$. ano, antes e depois da implementação do MDG.

Palavras-chave: modelo didático do género; sequência de ensino; exposição escrita; ensino básico. 


\begin{abstract}
In this text, partial results from a study will be presented. Said study aimed to analyse and understand how the writing practices implemented by teachers would impact the quality of students' produced texts. In order to meet the stated issue, a general goal was set: to assess whether a didactic device, the Genre Didactic Model (GDM), implemented in an explicit and intentional way by teachers, could be reflected, and to what extent, on the quality of the students' produced texts. The study was conducted as part of a training program for the teaching written genres in schools and it involved 14 teachers from the three cycles of compulsory education (in Portugal, basically K1-K9). The results here presented aim to highlight the characteristics of fourth grade students 'production of a written exposition before and after the implementing of the GDM.
\end{abstract}

Keywords: genre didactic model; teaching sequence; written exposition; compulsory education.

\title{
1. Apresentação e contextualização do estudo
}

Escrever para aprender e aprender a escrever são as duas dimensões que funcionaram como orientadoras deste estudo. A primeira representa a importância que a escrita adquire no processo de construção de conhecimentos (Applebee, 1984; Bazerman et al., 2005; Catel, 2001; Emig, 1977; Tynjälä, Mason e Lonka, 2001), a segunda, por sua vez, pressupõe os intervenientes que, em contexto escolar, estão diretamente implicados na aprendizagem: o aluno que aprende e o professor que ensina e faz aprender.

Partindo do pressuposto de que o professor assume nesse processo de aprendizagem da escrita um papel fundamental, procurámos encontrar na literatura disponível um conjunto de razões que tiveram como objetivo explicar a "sobrevivência" de uma escrita que não é ensinada de forma intencional e sistemática, não sendo, por isso, aprendida (Blaser, 2007; Pereira, 2003, 2004). As razões encontradas foram múltiplas e variadas e centram-se quer nos conhecimentos e práticas dos professores, quer nos materiais que as regulam (e condicionam) (Blaser, 2007; Castelló, 2008; Dionísio, Pereira e Viseu, 2011) 
Contrastando com tais práticas de escrita "avulsas" e descontextualizadas (Pereira, 2003; 2004) emergem, do discurso científico de referência, dois dos princípios que considerámos deverem conformar a ação didática dos professores: o princípio da sequencialidade, ancorado na planificação e implementação de "um conjunto de atividades organizadas, de maneira sistemática, em torno de um género textual" (Dolz, Noverraz e Schneuwly, 2001; Schneuwly e Dolz, 2004), e o princípio da intencionalidade, que pressupõe o conhecimento aprofundado do objeto a ensinar. Assumimos, pois, que tais princípios se consubstanciam num trabalho didático em sequência, ancorado num Modelo didático do género (MDG), isto é, numa descrição das principais características de um género textual, tornando, assim, visível para o professor o que é importante ensinar face ao que os alunos já sabem (Pietro, Erard e Kaneman-Pougatch, 1996).

Desta forma, colocámos o enfoque numa proposta de construção de um MDG do género exposição escrita, fundamentado nos princípios e pressupostos do ISD (Interacionismo socio-discursivo) (Bronckart, 1997, 2003, 2004, 2006; Bronckart, Bain, Schneuwly, Davaud e Pasquier, 1985; Bronckart e Stroumza, 2002), cuja implementação nos diferentes anos e ciclos da escolaridade pressupunha a sua adaptação e adequação aos contextos reais dos alunos. Foi por isso desenhado um programa de formação de professores, no qual foi planificado e implementado um MDG cuja construção teve na base o modelo de ação da linguagem e o modelo de arquitetura textual propostos por Bronckart, tendo sido, porém, adaptado (i.e. didatizado, cf. figura. 1) quer aos conhecimentos teóricos adquiridos pelos professores nas diferentes sessões, quer às realidades efetivas dos alunos, cujas competências de escrita foram avaliadas, numa primeira fase, a partir de uma produção inicial proposta pelos professores. 
34.4

2018

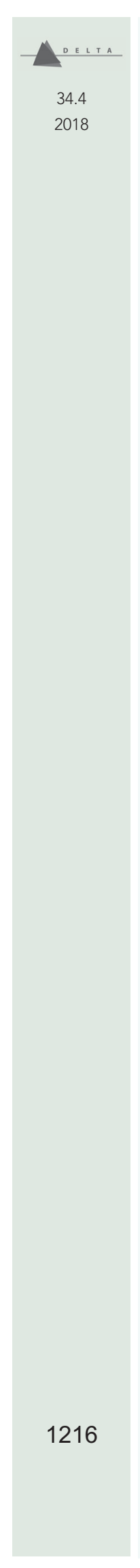

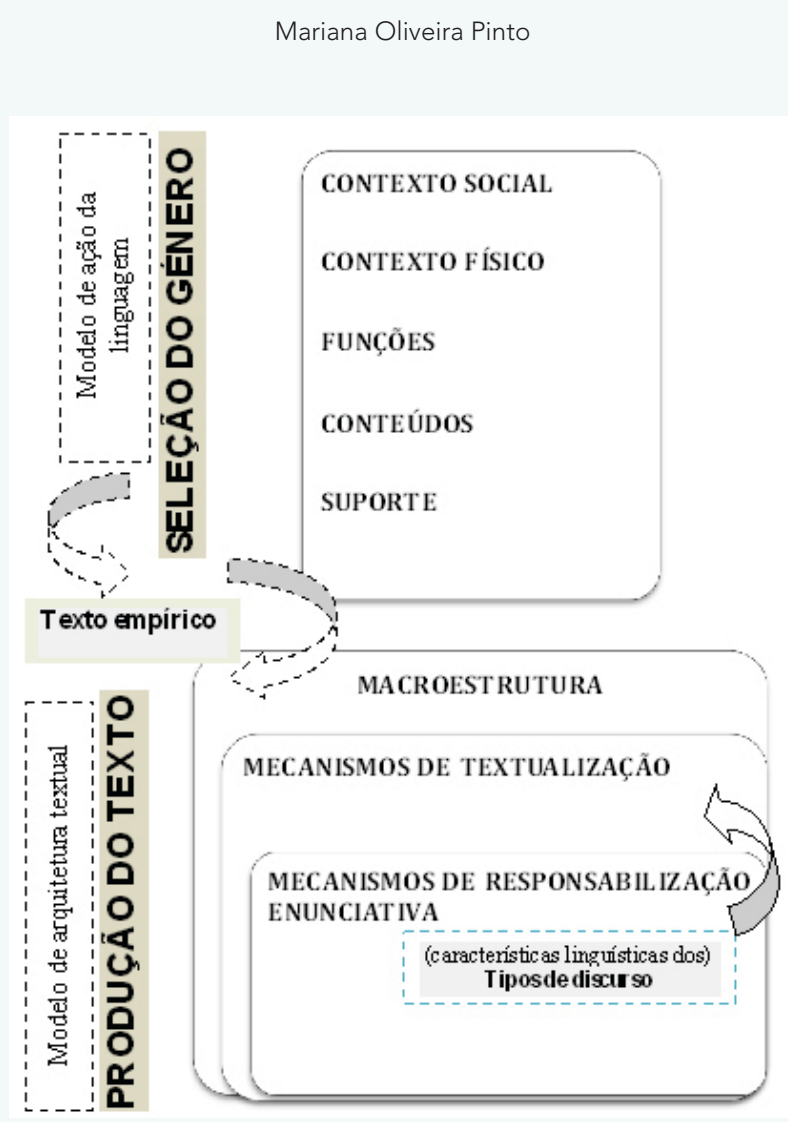

Figura 1 - Categorias consideradas no MDG construído a partir da perspetiva do ISD

A relação entre o que os professores ensinam e o que os alunos aprendem esteve na origem da formulação da questão inicial que enformou o estudo empírico realizado. Envolvendo um conjunto de professores do $1 .^{\circ}$ ciclo e professores de português do $2 .^{\circ}$ e $3 .^{\circ}$ ciclos, inscritos no programa de formação, procurámos perceber, mais objetivamente, de que modo as práticas de escrita que os professores implementam influenciam a qualidade dos textos que os alunos produzem.

No sentido de dar resposta à questão enunciada, definimos, como objetivo geral, avaliar se um dispositivo didático, o MDG, construído com base no conhecimento das propriedades dos géneros e dos textos, implementado de forma explícita e intencional pelos professores, 
pode refletir-se, e a que níveis, na qualidade dos textos que os alunos produzem.

Tal objetivo pressupôs o estabelecimento de diferentes fases do estudo, uma vez que foi necessário partir das práticas dos professores e alunos, antes da implementação do MDG, para, posteriormente, podermos analisar e avaliar, comparativamente, os resultados que este viesse a ter na qualidade dos textos dos alunos. Assim, cada fase pressupôs o estabelecimento de objetivos mais específicos, esquematizados na figura 2 :

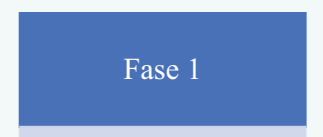

- caracterizar as práticas dos professores do ensino básico relativamente à dimensão escrever para aprender

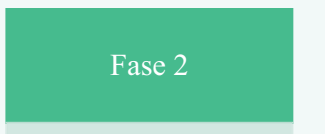

- caracterizar e compreender as práticas de escrita dos alunos do ensino básico

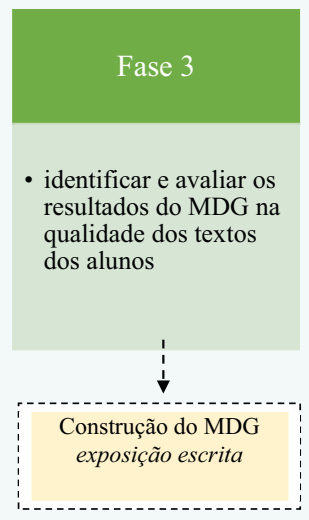

Figura 2 - Fases do estudo

A consecução dos objetivos definidos permitiu-nos, assim, (i) estabelecer um quadro configurador das práticas dos professores, a partir de uma proposta de atividade de seleção de informação e de escrita de uma exposição implementada em sala de aulas, na fase 1; (ii) identificar, numa turma do $4 .^{\circ}$ ano de escolaridade, as características dos apontamentos e dos textos produzidos, tarefas realizadas a partir das instruções dadas pelo professor na fase 2; e (iii) identificar, na fase 3 , as características dos apontamentos e dos textos produzidos pelos alunos depois de implementado o MDG, e analisar, comparativamente, os dados recolhidos nas fases 2 e 3 .

Nas duas primeiras fases foi possível estabelecer uma primeira relação entre a ação do professor e o entendimento que dela têm os alunos, e a última fase, ao centrar-se na identificação das diferenças ocorridas nos textos produzidos pelos alunos, relativamente à fase anterior, permitiu estabelecer, mais objetivamente, tal relação. 
Deste modo, os resultados obtidos nas três fases do estudo permitiram dar resposta à questão inicialmente definida, conduzindo às principais conclusões que passamos a apresentar. Nessa apresentação, seguimos uma linha condutora que, muito embora não estabeleça uma relação de causa e efeito, é, pelo menos, a apresentação de um percurso que envolve ação (dos professores) e reação (dos alunos) numa situação inicial de intervenção didática (antes da planificação e implementação do MDG) e numa situação final (depois de implementado o MDG). Por limitações de espaço, os resultados apresentados neste texto não incluem a dimensão "ler e selecionar informação" (seleção de conteúdos a textualizar, categoria incluída no modelo de acção da linguagem, cf. figura 1), centrando-se, apenas, na análise, também ela parcial, dos resultados relativos às categorias definidas para a análise dos textos produzidos (modelo de arquitetura textual): macroestrutura; mecanismos de textualização e mecanismos de responsabilização enunciativa (cf. figura 1).

Relativamente à macroestrutura, foram considerados, para este género textual específico, um plano do texto fixo: (i) introdução ( $1^{\circ}$. parágrafo): apresentação do objetivo, do tema e dos subtemas (hierarquizados); (ii) desenvolvimento: descrição e definição dos subtemas pela ordem apresentada na introdução (um parágrafo para cada subtema); (iii) conclusão ou remate: um parágrafo no qual se retoma o tema e se sintetizam os aspetos mais importantes, ou se remete para leituras complementares:

Nas categorias relativas aos mecanismos de textualização (conexão, coesão verbal e nominal) foram considerados (i) os estruturadores de informação com função de ordenação (em primeiro lugar; por último; por fim...); (ii) os tempos verbais no presente, $3^{\text {a }}$ pessoa e (iii) a apresentação e retoma dos temas.

\section{Apresentação e análise dos resultados do estudo}

Quando se acompanham, mais de perto, aquelas que são muitas das práticas escolares associadas à escrita, torna-se visível a permanência de um trabalho com a escrita e com os textos considerado como "um punhado de actividades e de exercícios que devem ser elaborados 
pelos alunos" (Pereira, 2008). De facto, tais práticas ancoradas numa rotina que ainda permanece, teimosamente, em algumas das nossas escolas, e com alguns professores, parecem dar alguma garantia do "dever cumprido", uma vez que os alunos, apesar de tudo, "escrevem alguma coisa". Aliás, e apesar de tudo o que já foi dito e escrito sobre a importância de se pensar a escrita como um processo complexo que exige tempo, intencionalidade e sequencialidade, no qual o professor deverá assumir o papel de mediador ${ }^{1}$, tal entendimento é ainda, para alguns professores, uma realidade ausente das estratégias e práticas que implementam nas suas aulas. Por razões de vária ordem, muito do que assumem fazer quando relatam as suas práticas, nem sempre representa aquilo que efetivamente fazem quando estão em situação de ação².

Ora, partindo da necessidade de conhecer os modos de ação dos professores envolvidos na formação, foi-lhes solicitada a planificação e implementação em sala de aula de uma atividade de produção de uma exposição escrita, de acordo com as suas práticas habituais.

Na verdade, o que está aqui em causa não é tanto a análise das suas práticas efetivas durante a implementação da atividade ou atividades planificadas, aspetos a considerar em outros contextos, mas sim os seus modos de agir quando propõem aos alunos a produção de um texto, neste caso específico, de uma exposição escrita. Assim, e partindo das suas próprias descrições daquilo que habitualmente caracteriza uma "aula de escrita"3, procurou perceber-se quais as instruções dadas aos alunos para a leitura e seleção de informação e para a escrita do texto, e quais os critérios que definem na avaliação dos textos produzidos.

1. Na impossibilidade de se referirem todos os autores, apenas algumas referências a título de exemplo: Angulo, Marugán e López, 2007; Barbeiro e Pereira, 2007; Barré-De-Miniac, 2003; Hayes, 1996; Pereira, 2005; Pereira, 2008; Pereira, Aleixo, Cardoso e Graça, 2010; Pereira e Pinto, 2008; Pinto, 2013, novembro; Pinto e Silva, 2010).

2. Na verdade, estes professores afirmaram trabalhar a escrita numa perspetiva de "oficina", muito embora tal designação, como se veio a perceber mais tarde, tenha o significado de "aula dedicada à escrita de um texto, a partir de uma proposta do professor ou do manual, na qual os alunos produzem um texto" (Pinto, 2013).

3. De acordo com o relato dos professores envolvidos, "nas aulas dedicadas à escrita começamos por propor aos alunos o tipo de texto a produzir (hoje vão escrever um texto...) e damos algumas indicações (ou cuidados a ter), nomeadamente com os erros, correção sintática e organização do texto" (Pinto e Pereira, 2013). 
São, pois, alguns dos resultados obtidos na análise das suas propostas que se apresentam no próximo ponto. Como já referimos, por limitações de espaço, os resultados apresentados neste texto são parciais, e não incluem, por isso, a dimensão "ler e selecionar informação" (seleção de conteúdos a textualizar), centrando-se, apenas, na análise, também ela parcial, dos resultados relativos à produção do texto: instruções dos professores e práticas dos alunos ${ }^{4}$.

2.1. Fases 1 e 2 - Práticas dos professores e alunos antes da implementação do MDG: o que é (e o que implica) escrever uma exposição escrita para os professores e alunos?

A partir dos dados recolhidos, concluímos que os professores demonstram algum desconhecimento relativamente às características do género e dos textos a produzir pelos alunos. Tratando-se de um género transversal aos três ciclos do ensino básico, sendo aliás um género a avaliar nos exames nacionais do $9 .^{\circ}$ ano, verificou-se que o entendimento que os diferentes professores têm sobre as suas características é distinto e, em alguns casos, impreciso, podendo ser considerado "um trabalho escrito", "um resumo", "um texto escrito com os apontamentos".

A pouca especificidade atribuída ao género em questão pelos professores foi igualmente visível a partir dos critérios de avaliação que definiram. Aliás, os critérios apresentados parecem decorrer de uma lista de tópicos que fazem parte, tradicionalmente, do léxico específico da disciplina, comuns, por isso, a qualquer texto de qualquer género considerado no Programa da disciplina: "organização do texto", "coesão", coerência", etc., não tendo havido, no entanto, qualquer especificação de cada um dos critérios apresentados.

Face às instruções dadas pela professora da turma em análise (4 ${ }^{\circ}$ ano): "escreve uma exposição escrita, isto é, um texto sobre a enguia com os apontamentos que tiraste", constatámos que os alunos realizaram a tarefa de escrita do texto assumindo-a como cópia dos apontamentos (que por sua vez eram cópias dos textos-fonte ${ }^{5}$ ) utili-

4. No artigo de Pinto e Pereira (2016) são apresentados estes resultados de forma mais desenvolvida.

5. Consideram-se textos-fonte os textos distribuídos aos alunos para leitura e seleção de informação sobre o tópico a desenvolver. Neste caso, foram distribuídos 2 textos (textofonte 1 e texto-fonte 2) sobre o tema enguia. O primeiro apresenta uma mancha gráfica 
zando, fundamentalmente, estratégias de supressão e substituição de palavras ou de partes de frases, tentando, assim, evitar a cópia integral. Tais estratégias resultaram em "textos" compostos por frases, sem qualquer articulação entre si (como é visível no exemplo apresentado na figura 3), que os alunos produziram para cumprir uma tarefa que demonstraram não saber (como) realizar.

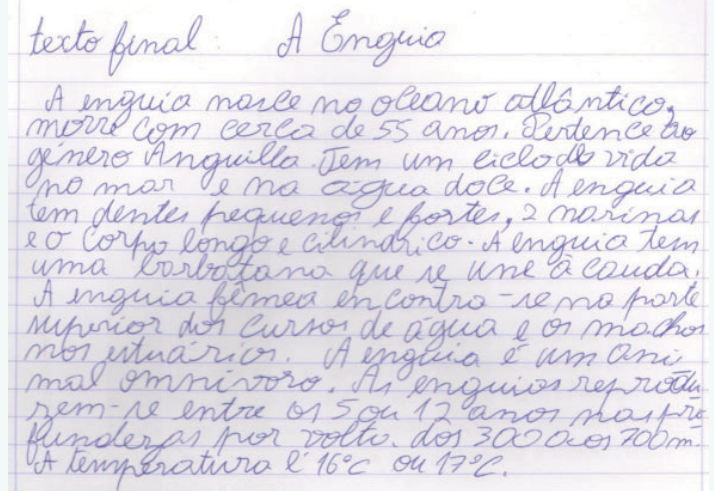

Figura 3 - Texto do aluno $\mathrm{A}_{21}$, fase 2 .

Para além deste aspeto, pudemos verificar que os alunos não organizaram o texto em parágrafos, assumindo, mesmo, em alguns casos, um parágrafo único na apresentação dos diferentes subtemas (figura 3). Confirmámos, assim, à imagem do que já foi considerado em outros estudos (Dolz, Rosat e Schneuwly, 1991; Schneuwly, Rosat e Dolz, 1989), que as dificuldades dos alunos dizem respeito, desde logo, à planificação e ao plano do texto.

As dificuldades identificadas nos textos dos alunos não estão circunscritas às questões do plano do texto. De facto, para além dos problemas relativos à pontuação, ortografia e sintaxe, de que a maior parte dos textos sofre, as dificuldades dos alunos fazem-se sentir, igualmente, ao nível das questões de conexão, coesão verbal e nominal, das quais se apresentam alguns exemplos a título ilustrativo.

próxima do artigo de enciclopédia (com subtítulos), o segundo, um texto retirado de um manual escolar, sem subtítulos. 


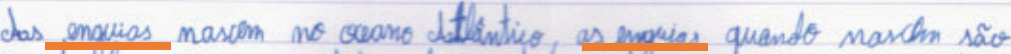

Figura 4 - Dificuldades dos alunos na coesão nominal, fase 2 - excerto do texto do aluno aluno $\mathrm{A}_{5}$.

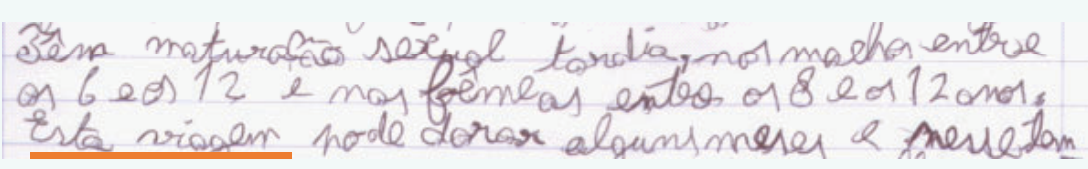

Figura 5 - Dificuldades dos alunos na coesão nominal, fase 2- excerto do texto do aluno aluno $\mathrm{A}_{4}$.

Para além dos aspetos já referidos, a leitura e análise dos textos dos alunos permitiu estabelecer um conjunto de estratégias mais utilizadas na produção dos textos. Tratando-se de uma produção textual realizada a partir da seleção de informação de conteúdos apresentados em outros textos, os alunos, em muitos casos, limitaram-se à cópia de frases suprimindo, inserindo ou substituindo palavras ou grupos de palavras.

Na cópia de frases com supressão, que afeta a sua gramaticalidade, o aluno retira palavras de uma frase. Nestes casos, a frase produzida apresenta problemas de natureza sintática (e semântica) pela ausência de um ou mais constituintes obrigatórios (grupo nominal ou verbal) ou de argumentos selecionados pelo verbo, nome ou adjetivo. Um exemplo de supressão verifica-se na produção do aluno $\mathrm{A}_{2}$ :

Após um longo ciclo de vida dentro de água continentais entre 5, e 12 anos. Este animal passa a sua vida dentro da água doce emigra ocorre entre os 6 anos e os $12 \operatorname{anos}\left(\mathrm{A}_{2}\right)$.

Outra estratégia utilizada foi a substituição de palavras ou expressões que provoca, muitas vezes, incorreções de natureza científica, como se verifica no exemplo seguinte: 
"A enguia é um peixe" (texto-fonte 2), assumido pelo aluno como mamífero, como se pode ver no excerto seguinte:

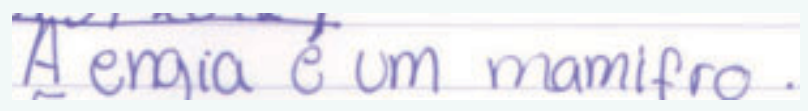

Figura 6 - Estratégias de textualização, fase 2. Excerto do texto do aluno $\mathrm{A}_{17}$.

Os casos de inserção de palavras podem ter como consequência a utilização de léxico não adequado. A propósito da caracterização da enguia, o aluno escreve:

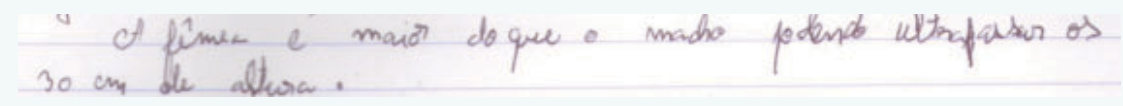

Figura 7 - Estratégias de textualização, fase 2 - excerto do texto do aluno $\mathrm{A}_{12}$.

Uma outra estratégia utilizada foi a contração da informação. Tal estratégia afeta a cientificidade dos conceitos, embora as frases produzidas sejam, na maior parte dos casos, gramaticalmente corretas, como se pode verificar no exemplo seguinte. No primeiro caso, o texto-fonte refere que "A fêmea é maior do que o macho, atingindo normalmente medidas que vão dos $30 \mathrm{~cm}$ a $1 \mathrm{~m}$ ”. Referindo-se a esta característica, o aluno escreve:

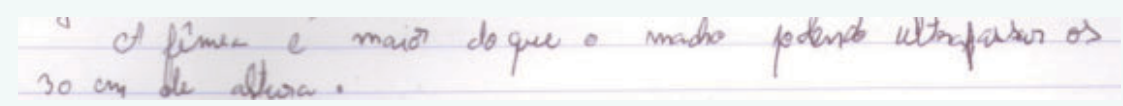

Figura 8 - Estratégias de textualização, fase 2. Excerto do texto do aluno $\mathrm{A}_{10}$.

Num outro exemplo, pode ler-se, no texto fonte 2: "Esta espécie foi ao longo dos séculos penetrando em quase todos os estuários da maior parte dos países europeus...". 
Na sua produção, o aluno escreveu:

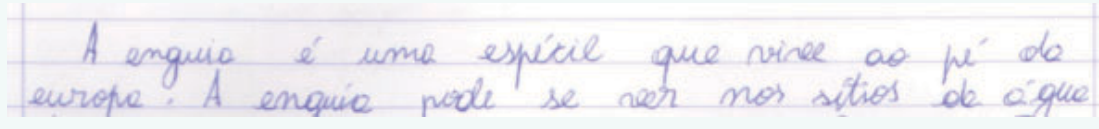

Figura 9 - Estratégias de textualização, fase 2. Excerto do texto do aluno $\mathrm{A}_{18}$

Face àquelas que foram as características evidenciadas nos textos dos alunos, parecia adquirir maior visibilidade a necessidade de um ensino (e de uma aprendizagem) da escrita assente no princípio da sequencialidade, contrária, por isso, às atividades pontuais e descontextualizadas, ancorado na planificação e implementação de "um conjunto de atividades organizadas, de maneira sistemática, em torno de um género textual" (Dolz, Noverraz e Schneuwly, 2004: 82; Schneuwly e Dolz, 2001).

A adoção de tal princípio implicou que as atividades a implementar com os alunos tenham tido na base um conhecimento aprofundado do objeto a ensinar por parte dos professores implicados no estudo. Assim, cada professor construiu um MDG, nele fazendo emergir quer os aspetos que considerou fundamental desenvolver com os respetivos alunos, face às características dos textos dos alunos, quer a sua própria visão (e nesse sentido compreensão) dos constructos teóricos que o configuram. Esta opção pretendeu, assim, alterar a tendência de "as ferramentas didácticas serem elaboradas tão-só com base na análise dos saberes a ensinar e nas próprias aprendizagens discentes, sem que sejam tidos em conta, muito particularmente, os saberes e os saberesfazer dos professores que as iriam utilizar" (Graça, 2010: 573).

\subsection{Fase 3 - Práticas dos professores: implementação do MDG}

Uma vez que se pretendia analisar comparativamente a produção inicial realizada na fase 2 (março) e a produção final, correspondente à fase 3 (maio), o tema e os textos-fonte distribuídos na produção final corresponderam aos apresentados na produção inicial (fase 2). Os procedimentos foram, também, os mesmos: no primeiro dia a leitura 
recurso, apenas, à folha de apontamentos produzida. Entre a produção inicial e a produção final foi implementada a sequência didática, para a qual a professora da turma definiu e planificou os diferentes módulos, depois de selecionados os conteúdos considerados mais importantes a desenvolver, de acordo com as dificuldades demonstradas nas primeiras produções textuais dos alunos (Cf. figuras 10a e 10b).

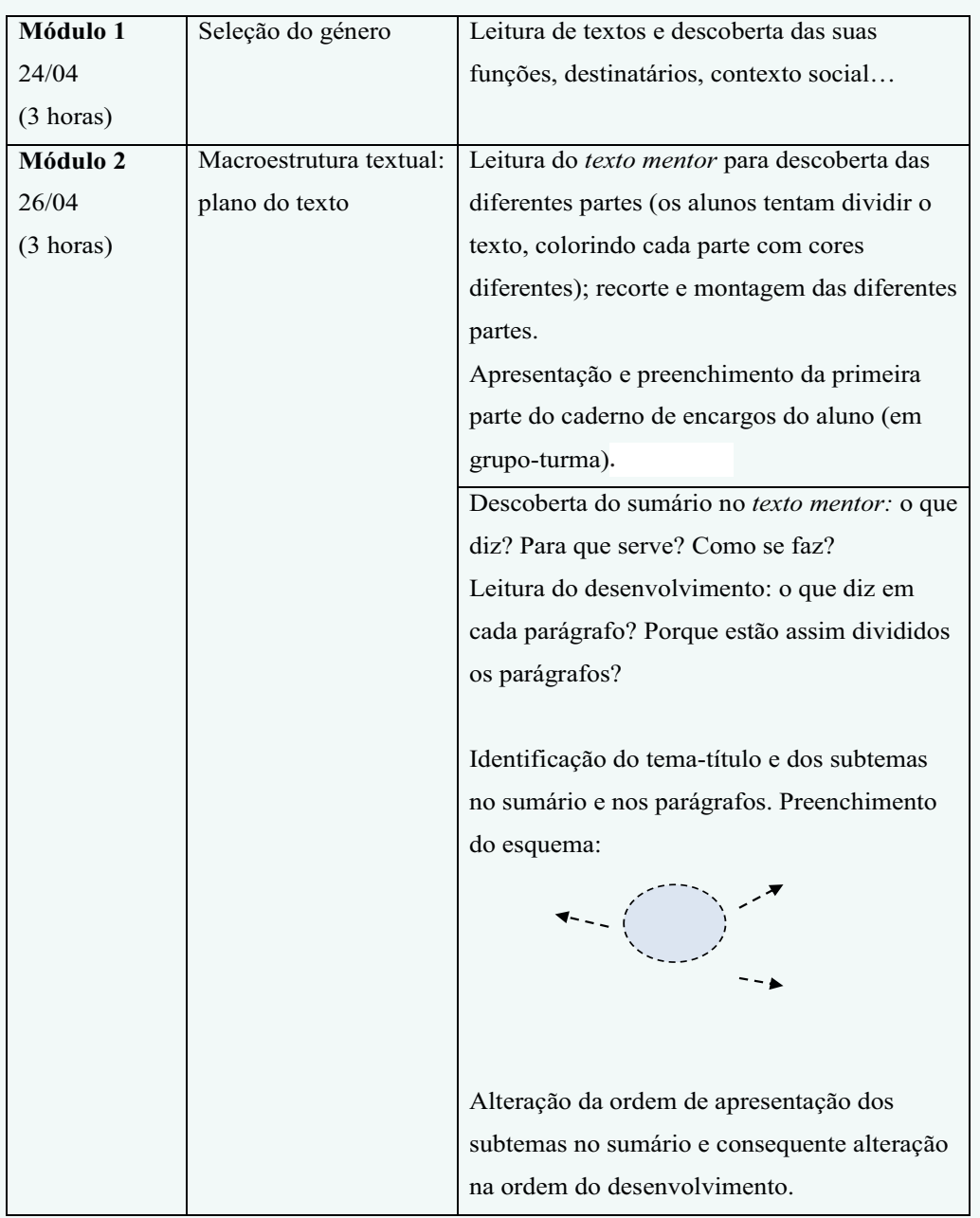

Figura 10a - Módulos da sequência didática 


\begin{tabular}{|c|c|c|}
\hline \multirow[t]{3}{*}{$\begin{array}{l}\text { Módulo } 3 \\
27 / 04 \\
30 / 04 \\
\text { (6 horas) }\end{array}$} & \multirow[t]{3}{*}{$\begin{array}{l}\text { Mecanismos de } \\
\text { textualização: } \\
\text { Conexão: } \\
\text { Estruturadores de } \\
\text { informação e conetores } \\
\text { discursivos }\end{array}$} & $\begin{array}{l}\text { Identificação dos estruturadores de } \\
\text { informação: } \\
\text { palavras usadas no sumário; no início dos } \\
\text { parágrafos. } \\
\text { Preenchimento da folha do caderno de } \\
\text { encargos (preenchimento individual; correção } \\
\text { em grupo-turma). }\end{array}$ \\
\hline & & $\begin{array}{l}\text { Leitura de outros textos mentores (de outros } \\
\text { grupos de formação): descoberta da } \\
\text { introdução, do desenvolvimento e } \\
\text { fechamento; identificação no sumário dos } \\
\text { subtemas e número de parágrafos } \\
\text { correspondentes no desenvolvimento; } \\
\text { identificação dos estruturadores de } \\
\text { informação. } \\
\text { Completar o caderno de encargos com as } \\
\text { novas palavras. }\end{array}$ \\
\hline & & $\begin{array}{l}\text { Produção intermédia }(02 / 05) \\
\text { Individual }\end{array}$ \\
\hline \multirow[t]{2}{*}{$\begin{array}{l}\text { Módulo } 4 \\
02 / 05 \\
3 \text { horas }\end{array}$} & \multirow[t]{2}{*}{$\begin{array}{l}\text { Coesão verbal e coesão } \\
\text { nominal }\end{array}$} & $\begin{array}{l}\text { Leitura para descoberta dos tempos verbais; } \\
\text { identificação das formas verbais (léxico); } \\
\text { apresentação dos temas e retomas. (esta, essa, } \\
\text { ela, ele...). }\end{array}$ \\
\hline & & $\begin{array}{l}\text { Elaboração de grelhas de autoavaliação. } \\
\text { Leitura, autoavaliação e reescrita das } \\
\text { produções intermédias de acordo com os } \\
\text { aspetos definidos no caderno de encargos. }\end{array}$ \\
\hline $\begin{array}{l}04 / 05 \\
05 / 05\end{array}$ & & $\begin{array}{l}\text { Produção final: } \\
\text { leitura e seleção de informação } \\
\text { produção textual: exposição escrita }\end{array}$ \\
\hline
\end{tabular}

Figura 10b - Módulos da sequência didática

Em cada um dos módulos, os alunos construíram um conhecimento mais aprofundado do género exposição escrita, a partir da leitura e identificação das suas características nos textos modelares. 


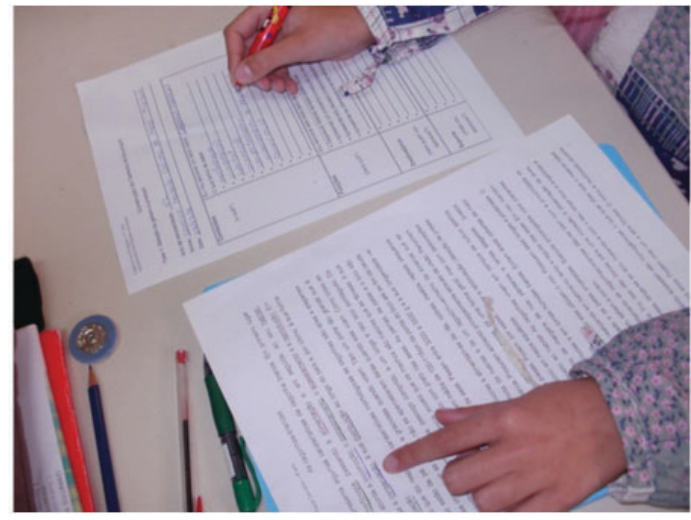

Figura 11 - Leitura para descoberta das características do texto

Todos os conteúdos trabalhados deram origem à construção do Caderno do aluno. Nas diferentes partes (ou secções), iam registando a informação recolhida na leitura dos textos modelares. O exemplo seguinte ilustra a página relativa aos mecanismos de conexão identificados pelo aluno:

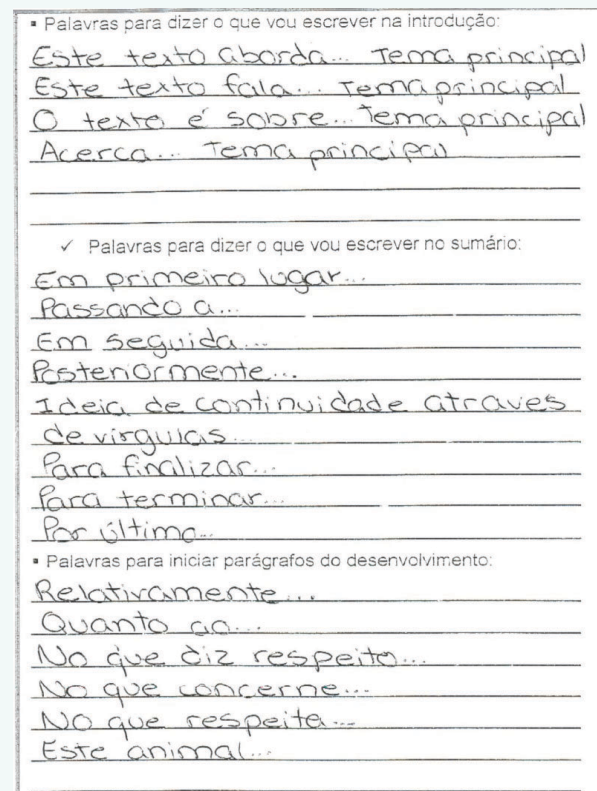

Figura 12 - Página do caderno do aluno 
34.4

2018

Todas as categorias trabalhadas deram origem, posteriormente, a grelhas de autoavaliação dos textos, que os alunos preencheram em cada produção textual realizada. Na figura 12 estão representadas, a título de exemplo, a grelha relativa às categorias trabalhadas no plano do texto e, na figura 13, a grelha preenchida por um aluno após a realização de uma produção intermédia de escrita:

\begin{tabular}{|c|c|c|c|c|}
\hline & & sim & กล̃̃o & Revisão e reescrita ( $\circ$ que vou alter ar) \\
\hline \multirow{15}{*}{ 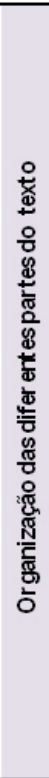 } & $\begin{array}{l}\text { Selecionei os conteúdos } \\
\text { de acordo com o(s) }\end{array}$ & & & \\
\hline & objetivo(s) do texto? & & & \\
\hline & O texto tem título? & & & \\
\hline & $O$ texto tem uma & & & \\
\hline & introduçãa? ? & & & \\
\hline & $\begin{array}{l}\text { Aoresento o objetivo, o } \\
\text { tema e os subtemas? }\end{array}$ & & & \\
\hline & & & & \\
\hline & $\begin{array}{l}\text { desenvolvimento? } \\
\text { dent ves }\end{array}$ & & & \\
\hline & Aoresento os subtemas & & & \\
\hline & apresentei na & & & \\
\hline & introduçăo? & & & \\
\hline & $\begin{array}{l}\text { Cada parágrafo } \\
\text { apresenta um subtema? }\end{array}$ & & & \\
\hline & & & & \\
\hline & $O$ texto tem uma & & & \\
\hline & $\begin{array}{l}\text { conclusao ou } \\
\text { fechament o? }\end{array}$ & & & \\
\hline
\end{tabular}

Figura 13 - Grelha de auto-avaliação I 
Figura 14 - Grelha de auto-avaliação I preenchida por um aluno

2.3. Fase 3 - Práticas dos alunos depois da implementação do MDG: o que é (e o que passou a implicar) escrever uma exposição escrita para os alunos?

As duas fases anteriormente apresentadas permitiram estabelecer uma relação entre as práticas dos professores e os desempenhos demonstrados pelos alunos na escrita do texto.

Após a implementação dos módulos da sequência didática, planificados e desenvolvidos a partir do MDG, a fase 3 permitiu caracterizar as práticas e os produtos escritos dos alunos da turma do $4 .^{\circ}$ ano de escolaridade, tendo por base a análise dos textos produzidos. Foi possível, assim, mais objetivamente, responder à questão orientadora do estudo, que aqui se retoma: de que modo poderá um MDG cons- 
truído com base no conhecimento das propriedades dos géneros e dos textos, implementado e desenvolvido de forma explícita e intencional pelos professores, refletir-se na qualidade dos textos que os alunos produzem?

Um dos aspetos que imediatamente ressaltava da leitura dos textos dos alunos na fase 2 dizia respeito, para além das dificuldades de organização do texto em parágrafos, à ausência de um parágrafo introdutório que apresentasse o tema e o objetivo (ou objetivos) do texto, aspeto considerado fundamental numa exposição escrita.

A partir dessa constatação, um dos módulos trabalhados com os alunos centrou-se, como já referimos, no plano do texto, tendo-se estabelecido, então, um plano fixo organizado em três partes constitutivas: (i) a introdução, na qual os alunos deveriam apresentar o tema, os objetivos do texto e os subtemas a desenvolver por uma determinada ordem; (ii) o desenvolvimento, cuja apresentação dos temas deveria seguir a ordem escolhida na introdução, e (iii) um fechamento, que implicava remeter o leitor para outras fontes ou retomar o objetivo inicial como remate do texto.

Tendo estes elementos do plano por base, foram analisados os textos dos alunos e identificada a percentagem daqueles que produziram o texto final de acordo com as três categorias definidas.

A conclusão a que se chegou foi a de que todos os alunos produziram o texto com uma introdução e um desenvolvimento. Já a categoria fechamento, talvez a mais difícil de compreender para os alunos, foi apresentada, no entanto, por $77 \%$ dos alunos.

$\mathrm{Na}$ análise das diferentes introduções dos alunos, foram tidas em consideração as diferentes características definidas no MDG, com base nas quais se procurou identificar, em cada uma das introduções, o objetivo, o tema e os subtemas a desenvolver.

De facto, também nestas categorias os alunos demonstraram um bom desempenho, como se exemplifica no excerto de um texto de um aluno (figura 15), uma vez que elas estão presentes em $86 \%$ das introduções dos alunos. 


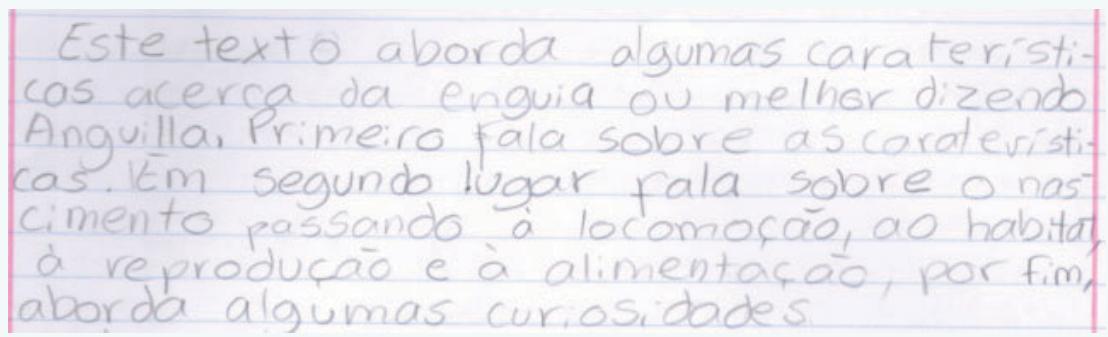

Figura 15 - Organização do texto, fase 3 - excerto do texto do aluno $\mathrm{A}_{14}$.

Embora, como se viu, todos os alunos tenham considerado a introdução nos seus textos, há casos em que a estas faltam um dos elementos definidos, como se ilustra no exemplo da figura seguinte na qual se apresenta um excerto de uma introdução de um aluno à qual falta a apresentação do tema:

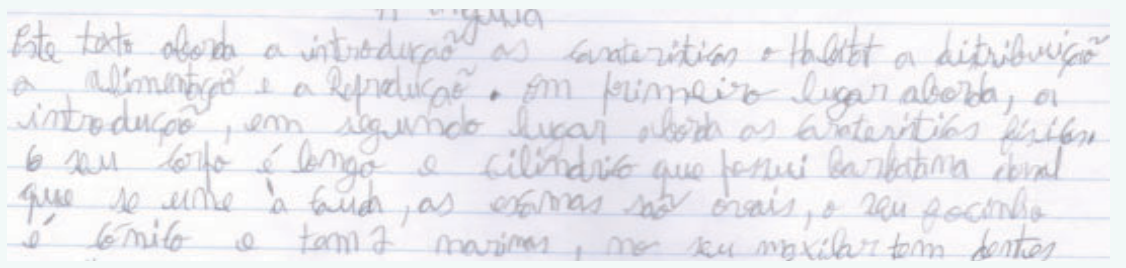

Figura 16 - Dificuldades dos alunos na introdução, fase 3 - excerto do texto do aluno $\mathrm{A}_{1}$

O aluno apresenta os subtemas que vai desenvolver, incluindo a introdução que é um dos subtítulos do texto-fonte, mas não refere o tema, talvez por entender que o facto de este estar no título do texto, significa que não é necessário voltar a referi-lo.

Outro aspeto que decorre da análise efetuada diz respeito às dificuldades manifestadas por alguns alunos na construção da introdução. Para além dos casos que incluem a designação introdução nos subtemas, como no exemplo da figura anterior ("Este texto aborda a introdução...), outros alunos manifestam algumas dificuldades a nível sintático, nomeadamente, problemas de subcategorização, como no exemplo: "este texto aborda de informação sobre a enguia". 
Uma característica também muito visível nas produções dos alunos diz respeito à atribuição dos traços [+ humano] ao texto: "o texto fala; o texto aborda", justificada pela apresentação destes termos pela professora da turma.

Na parte do desenvolvimento, procurou analisar-se, por um lado, se os subtemas desenvolvidos correspondiam àqueles que foram apresentados na introdução e, por outro, se os subtemas apresentados seguiam a ordem definida na introdução. Para além destes aspetos, analisaram-se os parágrafos do desenvolvimento no sentido de perceber se cada um deles correspondia a um subtema específico.

Os dados recolhidos permitiram verificar que $91 \%$ dos alunos seguiram a ordem dos subtemas apresentados e construíram o texto em parágrafos, fazendo corresponder a cada um deles um subtema diferente.

Relativamente ao fechamento do texto, os alunos que não o apresentaram parecem demonstrar não ter percebido como realizá-lo. Com efeito, no preenchimento da grelha de autoavaliação selecionaram a coluna do não (não tem) mas não reescreveram o texto. Este aspeto é particularmente importante, uma vez que torna visível, por um lado, que os alunos reviram o texto em função da grelha de avaliação e, por outro lado, que identificaram os itens a rever com algum rigor.

Para além disso, e esta é uma consideração que merece algum destaque, estes alunos apresentam já uma capacidade de reflexão sobre as suas próprias dificuldades, face aos conhecimentos adquiridos. $\mathrm{Na}$ verdade, a tomada de consciência de que não sabem como concretizar um aspeto pedido (ou exigido) na produção textual tem, obviamente, um significado muito diferente de não saber sequer que tal aspeto é pedido, ou a que é que se refere.

Os desfechos apresentados são, na sua maioria, os finais "possíveis". Não tendo muito mais a acrescentar sobre o tema e não havendo qualquer conclusão a retirar face ao que foi dito, usaram o exemplo que foi sendo apresentado nos diferentes módulos pela professora:

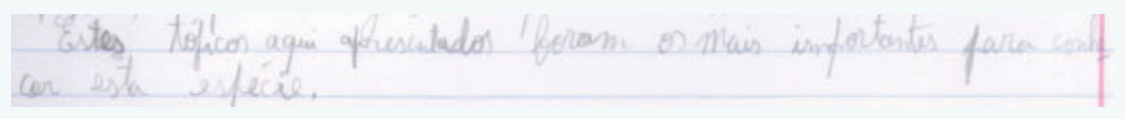

Figura 17 - Excerto do fechamento do texto do aluno $\mathrm{A}_{19}$. 
No entanto, também foram identificados alguns desfechos que pretendiam ir para além do que foi dito no texto, e acrescentar alguma informação mais:

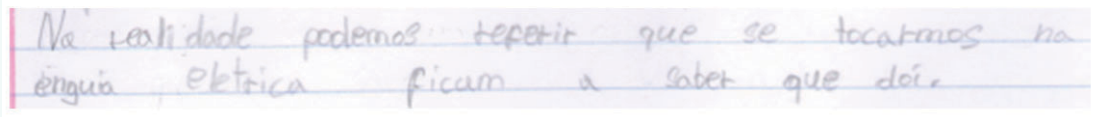

Figura 18 - Excerto do fechamento do texto do aluno $\mathrm{A}_{11}$

Num outro nível de análise, correspondente à camada intermédia do "folhado textual", os mecanismos de textualização, foram analisados os textos produzidos e recolhidos os exemplos que pudessem dar conta, também a este nível, de que os conteúdos identificados no MDG e trabalhados nos módulos foram de alguma forma compreendidos e utilizados pelos alunos.

Face às dificuldades demonstradas pelos alunos na produção do texto na fase 2 , foram previstos módulos de trabalho centrados no desenvolvimento dos mecanismos de textualização considerados no MDG como fundamentais para os alunos em questão. Foram, ainda, analisadas, porque consideradas no MDG, outras características linguísticas: utilização de frases declarativas; utilização da $3 .^{a}$ pessoa e de adjetivos de valor específico.

Relativamente à utilização dos estruturadores de informação, a análise dos textos permite concluir que $65 \%$ dos alunos os utilizou na escrita do texto, o que contrasta claramente com os resultados da fase 2 , em que nenhum texto apresentava estruturadores de informação.

Foi igualmente possível verificar que os estruturadores de informação foram mais utilizados na introdução ( $91 \%$ dos alunos) do que na abertura dos parágrafos, uma vez que apenas $50 \%$ dos alunos os utilizou nesse contexto. O excerto seguinte exemplifica um desenvolvimento sem estruturadores: 


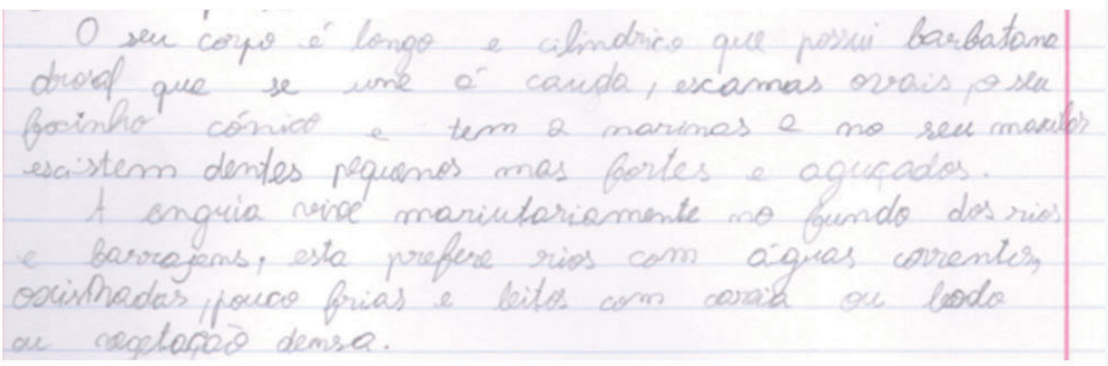

Figura 19 - Dificuldades dos alunos, fase 3 - mecanismos de textualização. Excerto do texto do alunoA18.

$\mathrm{Na}$ construção do parágrafo relativo à introdução, procurou-se identificar o modo como os alunos utilizaram os estruturadores de informação, uma vez que teriam de apresentar vários subtemas (num máximo de 8). Assim, teriam de optar ou por selecionar um estruturador para cada subtema, ou agrupar diferentes subtemas e apresentá-los utilizando um número menor de estruturadores. Na realidade, e como se pode ver no exemplo seguinte, alguns alunos optaram por apresentar os subtemas utilizando, para cada um, um estruturador:

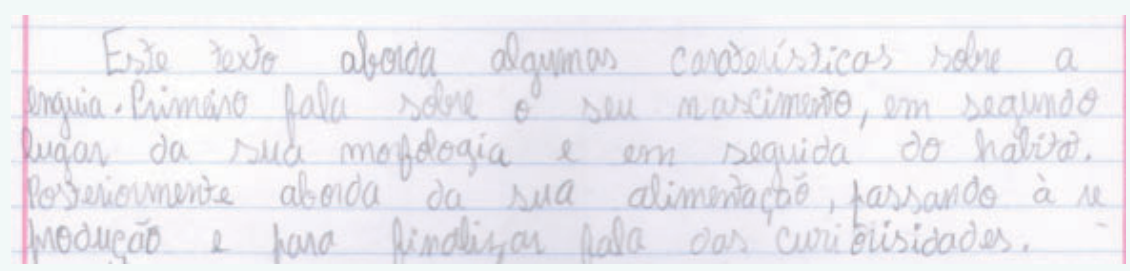

Figura 20 - Utilização dos estruturadores de informação, fase 3. Excerto do texto do aluno A22.

Outros, no entanto, optaram por agrupar os subtemas, utilizando, assim, um menor número de estruturadores: 


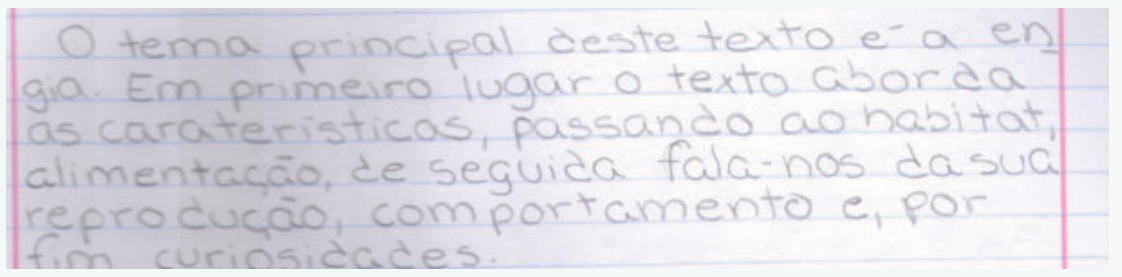

Figura 21 - Utilização dos estruturadores de informação, fase 3. Excerto do texto do aluno A2.

Como já foi referido, os textos dos alunos apresentam uma característica comum a quase todos. Na introdução, ao termo "texto" é atribuído o traço de [+ humano]. Na verdade, este é um problema que não pode ser imputado aos alunos, uma vez que eles se limitam a utilizar a expressão partindo das possibilidades que foram apresentadas pela professora.

Como se pode ver no excerto de um dos CdE de um aluno (figura 22), nas possibilidades de "início do texto" figuram os exemplos "o texto fala" e "o texto aborda":

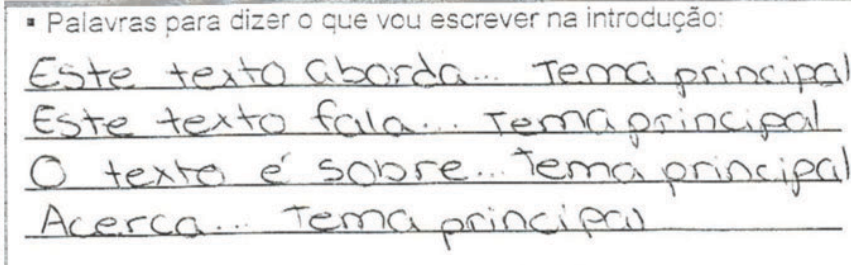

Figura 22 - Excerto do caderno dos alunos.

Para além desta dificuldade, diretamente associada aos módulos, há uma outra, também ela a merecer uma reflexão e, claro, a consideração numa próxima sequência, que diz respeito à utilização dos diferentes estruturadores de informação ao longo do texto. 
No exemplo seguinte, o aluno revela alguns problemas no estabelecimento da ordem de apresentação, utilizando "em segundo lugar" de forma desadequada:

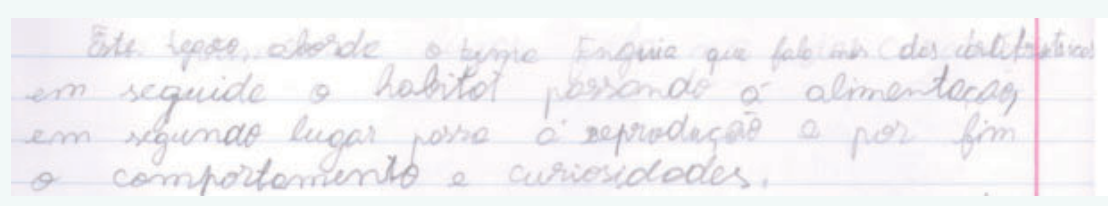

Figura 23 - Dificuldades dos alunos, fase 3. Utilização dos estruturadores de informação. Excerto do texto do aluno A22.

As maiores dificuldades identificadas na utilização dos estruturadores nas frases dos alunos são, no entanto, de natureza sintática, nomeadamente pela ausência de um dos argumentos essenciais - X dizer respeito a Y-, (figuras 24 e 25):

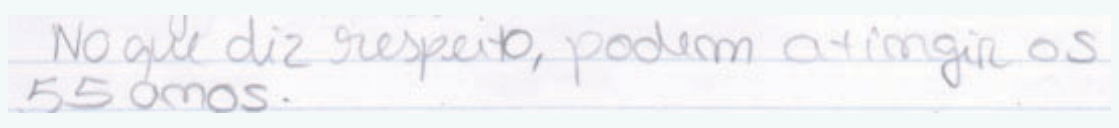

Figura 24 - Dificuldades dos alunos, fase 3. Utilização dos estruturadores de informação. Excerto do texto do aluno $\mathrm{A}_{12}$.

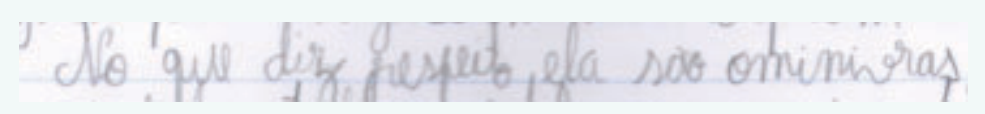

Figura 25 - Dificuldades dos alunos, fase 3. Utilização dos estruturadores de informação. Excerto do texto do aluno $\mathrm{A}_{5}$.

Tais dificuldades podem estar associadas ao facto de os alunos terem trabalhado os estruturadores apenas na perspetiva da sua funcionalidade (para que servem), não tendo sido previsto um módulo de trabalho centrado na explicitação do seu funcionamento sintático. $\mathrm{Na}$ verdade, quando se analisam os materiais que foram construídos com os alunos nos módulos, verifica-se que os estruturadores de informação ocorrem, na maior parte dos exemplos, sem as preposições, o que explica as dificuldades sentidas aquando da sua transposição para os textos. 
- Palavras para iniciar parágrafos do desenvolvimento:

Relativamente

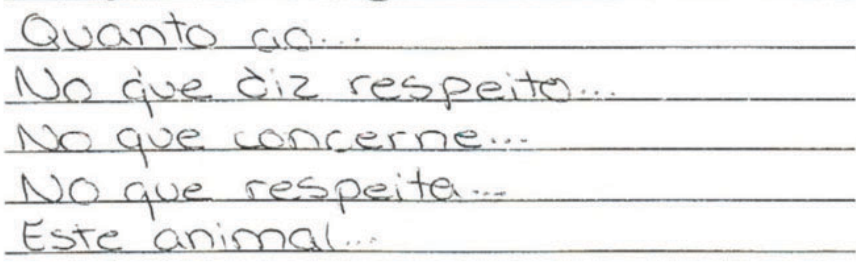

Figura 26 - Excerto do caderno dos alunos

Quer isto dizer que importa refletir e considerar a necessidade de definição, nos módulos, de um trabalho explícito dos aspetos gramaticais envolvidos na construção dos sentidos. De facto, sem esta tomada de consciência, pode correr-se, eventualmente, o risco de os alunos utilizarem estas expressões sem o conhecimento efetivo do seu significado. Tratando-se de expressões que não fazem parte do seu uso linguístico, não conseguem, por isso, aceder ao conhecimento implícito das "formas de as dizer", necessitando, por isso, de uma maior explicitação.

A questão da utilização dos estruturadores como se de uma lista se tratasse, pode também dar aos alunos a falsa impressão de que há alguns que só se usam na introdução, enquanto que outros se utilizam, por exemplo, no desenvolvimento.

\section{Considerações finais}

Apresentadas, assim, de forma geral, as conclusões mais relevantes, importa, face à questão inicial, fazer algumas considerações.

Embora, como já assumimos aqui, não tenha sido objetivo do estudo estabelecer uma relação de causa, uma vez que não foram consideradas as (muitas) variáveis que de algum modo pudessem tornar mais visível tal relação, ficou claro, pensamos, que os modos de agir dos professores se veem refletidos nos desempenhos dos alunos. Desde 
logo, pela compreensão (ou falta de compreensão) das tarefas a realizar. De facto, o desconhecimento da natureza (ou das características) do que é proposto provoca nos alunos a incerteza do que é esperado que façam. Pelo contrário, o conhecimento da natureza da tarefa a realizar, das suas implicações e elementos configuradores, mesmo que de uma forma ainda pouco consistente, faz com que, como vimos, o resultado da tarefa realizada pelos alunos se aproxime muito do que era esperado que fizessem.

Duas questões estão, porém, subjacentes à ideia anterior, sobre as quais importa refletir. A primeira diz respeito à continuidade, e a segunda diz respeito à intencionalidade das práticas. Se é verdade que os alunos conseguiram demonstrar um melhor desempenho na tarefa de escrita do texto, também é verdade que tais conhecimentos adquiridos serão rapidamente esquecidos se não forem assumidos como "prática a usar" e como ferramenta a utilizar em novas situações. Se não for assim, poderá correr-se o risco de os alunos considerarem a experiência como algo que começou e terminou no momento em que produziram e entregaram o texto, não sendo, por isso, capazes de mobilizar o que aprenderam em outras situações de escrita e de estudo.

As potencialidades do modelo apresentado implicam, pois, uma tomada de consciência profunda das diferentes variáveis implicadas na construção textual e dos modos da sua apropriação por parte dos alunos. Neste sentido, a sua produtividade didática fica, assim, diretamente dependente do entendimento que destas variáveis tiverem os professores.

No entanto, e aqui residirá uma das suas principais virtudes, enquanto modelo poderá permitir aos professores tornar visíveis algumas das características fundamentais do género e do texto a produzir, de um modo organizado, e fazer emergir quais as que devem ser trabalhadas num determinado ano ou ciclo. Foi neste sentido que propusemos a sua elaboração para um ciclo (ou ciclos) e não para um ano específico ou sequência concreta. Na verdade, acreditamos que poderá ser elaborado um único MDG para cada um dos géneros propostos pelo programa para o ensino básico. A partir dele, cada professor procederá à seleção dos conteúdos face ao ciclo/ano/turma/alunos. O MDG constituir-se-á, assim, também, um locus de definição dos critérios de progressão. 
Recebido em: 01/03/2016

Aprovado em: 28/03/2018

E-mail: mariana.opinto@gmail.com

\section{Referências}

Angulo, T. Á., D. P. Marugán, \& M. P. López. 2007. De cómo convertir un texto expositivo en argumentativo y sus implicaciones didácticas. Didáctica (lengua y Literatura), 19: 31-46.

Applebee, A. 1984. Writing and reasoning. Review of Educational Research, 54:4: 577-596.

Barbeiro, L., \& L. Á. Pereira. 2007. O Ensino da Escrita - a dimensão textual. Lisboa: DGIDC.

BARRÉ-DE-MINIAC, C. 2003. Ecrire pour apprendre: des pratiques à inventer. Résonances, 8: 4-9.

Bazerman, C., J. Little, L. Bethel, T. Cahvikin, D. Fouquette, \& J. GARUFIS. 2005. Reference guide to writing across the curriculum. USA: Parlor Press and The WAC Clearinghouse.

Blaser, C. 2007. Fonction épistémique de l'écrit: Pratiques et conceptions d'enseignants de sciences et d'histoire du secondaire. Ph. D. Faculté des Etudes Supérieures - Université Laval, Quebec.

BRoncKart, J.-P. 1997. Activité langagière, textes et discours: pour un interactionisme socio-discursif. Delachaux et Niestlé. 2003. Gêneros textuais, tipos de discursos e operações psicolinguísticas. Revista Estudos da Linguagem, Volume 11, 4969.

2004. Les genres de textes et leur contribution au développement psychologique. Langages ( $\left.\mathrm{N}^{\mathrm{o}} 153\right)$ : 98-108.

2006. Actividade de linguagem, discurso e desenvolvimento humano. Campinas, SP: Mercado das Letras.

Bronckart, J.-P., D. Bain, B. Schneuwly, C. Davaud, \& A. Pasquier. 1985. Le fonctionnement des discours: Un modèle psychologique et une méthode d'analyse. Paris: Delachaux et Niestlé.

Bronckart, J.-P., \& K. Stroumza. 2002. Les types de discours comme traces cristallisées de l'action du langage. In E. Roulet \& M. Burger. Eds. Les analyses de discours au défi d'un dialogue romanesque (pp. 213-263). Nancy: Presses Universitaires de Nancy.

CASTELLÓ, M. 2008. Escribir para aprender: estrategias para transformar el conocimiento. Aula, 175: 15-22. 
CATEL, L. 2001. Écrire pour apprendre? Ecrire pour comprendre. Aster(33): $17-47$.

Dionísio, M. D. L. D. T., M. D. C. D. M. E. Pereira, \& F. A. V. Viseu. 2011. A leitura e a escrita no currículo: a presença ausente. Atos de pesquisa em educação- Revista do Programa de pós-graduação da Universidade Regional de Blumenau (PPGE/FURB), 6(1): 94-114.

Dolz, J., M. NoverRaz, \& B. Schneuwly. 2001. S'exprimer en français: Séquences didactiques pour l'oral et l'écrit. (Vol. I-III.) Bruxelles: De Boeck \& Larcier.

Dolz, J., M. C. Rosat, \& B. Schneuwly. 1991. Elaboration et évaluation de deux séquences didactiques sur trois types de textes. Le français aujourd'hui, 93: 37-47.

EMIG, J. 1977. Writing as a model of learning. College Composition and Communication, 28.2: 122-128.

HAYES, J. 1996. A new framework for understanding cognition and affect in writing. In Levy, C. Michael \& Ransdell, Sarah. Eds. The science of writing theories, methods, individual differences, and applications. Mahwah (NJ): Lawrence Erlbaum Associates.

Pereira, L. A. 2003. Para uma Didáctica da Escrita no Ensino Básico: teses, pressupostos e condições de possibilidade. In A. Neto, J. Nico, J. C. Chouriço, P. Costa \& P. Mendes. Eds. Didácticas e Metodologias da Educação-Percursos e Desafios (pp. 109-116). Évora: Universidade de Évora.

. 2004. Imagem da escrita de docentes do ensino básico. Para uma (re)definição do papel do professor que ensina a escrever. In Actas VIII Congreso Sociedad Española de Didáctica de la Lengua y la Literatura (pp. 133-145). La Habana.

.2005. Escrita e trabalho na escola. Comunicação oral (Transcrição da comunicação). Porto: FPCE.

. 2008. Escrever com as crianças. Como fazer bons leitores $e$ escritores. Para crianças dos 0 aos 12 anos. Porto: Porto Editora.

Pereira, L. Á. 2008. Escrever com as crianças, como fazer bons leitores e escritores. Para crianças dos 0 aos 12 anos. Porto: Porto Editora.

Pereira, L. A., C. Aleixo, I. Cardoso, \& L. Graça. 2010. The teaching and learning of writing in Portugal: The case of a research group. In C. Bazerman, R. Krut, K. Lunsford, S. McLeod, S. Null, P. M. Rogers \& A. Stansell. Eds. Traditions of Writing Research (pp. 5870). Oxford, UK: Routledge.

Pereira, L. A., \& M. Pinto. 2008. Escrever para aprender: Experiências didácticas. In L. F. Barbeiro \& J. A. B. Carvalho. Eds. Actividades de escrita e aprendizagem. Leiria: Escola Superior de Educação do 
Instituto Politécnico de Leiria, Centro de Investigação em Educação (CIEd) - U. Minho (Editado em CD-ROM).

Pietro, J.-F. D., S. Erard, \& M. Kaneman-Pougatch. 1996. Un modèle didatique du débat: de l'objet social à la pratique scolaire. Enjeux, 39: 100-129.

PinTo, M. O. (2013, novembro). Escrever para aprender. Paper presented at the Formação sobre as metas curriculares, Universidade de Lisboa.

Pinto, M. O., \& E. Silva. 2010. Kit de actividades para o $1{ }^{\circ}$ ciclo. Lisboa: Texto Editores.

Pinto, M. O., \& Pereira, L. Á. (2016). Escrever para aprender no ensino básico: das conceções dos professores às práticas dos alunos. Revista Portuguesa de Educação, 29(2), pp. 109-139.

Schneuwly, B., \& J. Dolz (Eds.). 2004. Gêneros orais e escritos na escola. Campinas: Editora Mercado de Letras.

Schneuwly, B., M.-C. Rosat, \& J. Dolz. 1989. Les organisateurs textuels dans quatre types de textes écrits. Etude chez des élèves de 10, 12 et 14 ans. Langue française, 81(1): 40-58.

TyNJÄLÄ, P., L. MAson, \& K. LonkA. 2001. Writing as a Learning Tool An Introduction. In P. Tynjälä, L. Mason \& K. Lonka. Eds. Writing as a Learning Tool - Integrating Theory and Practice (pp. 7-22). Netherlands: Kluwer Academic Publishers. 